\title{
LA POSIBILIDAD DE APLICAR LA JURISDICCIÓN PENAL MEXICANA EN LA ZONA ECONÓMICA EXCLUSIVA* [OPINIÓN DEL MINISTRO JOSÉ RAMÓN COSSÍO DÍAZ]
}

[La SCJN ha emitido en el 2005 la resolución a un amparo directo en revisión que versa sobre la interpretación que la corte ha dado a la procedencia de la aplicación de la jurisdicción nacional en la Zona Económica Exclusiva cuando en ella se llevan a cabo actividades de extranjeros con fines ilícitos. Para muchos especialistas, y con gran preocupación por los efectos internacionales que se puedan reflejar a futuro en el derecho internacional, la máxima autoridad judicial del país mostró una postura incorrecta al considerar a la ZEE como parte del territorio nacional y no echar mano de tratados e interpretaciones doctrinales internacionalistas (como es el caso de la jurisdicción universal). Al parecer, una vez más el derecho nacional se presenta desfasado de la realidad internacional; en este caso, es el derecho internacional del mar donde se muestra la falta de vinculación de este derecho al ámbito doméstico.

Una de las posturas en contrario es la del ministro José Ramón Cossío Díaz como se explica a continuación con las reflexiones contenidas en su voto particular en relación con el Amparo Directo en Revisión 23/2005. Sin duda, el voto particular será un elemento de análisis por los estudiosos de la materia, por lo cual se reproduce a continuación.**]

Para explicar nuestra posición en el presente asunto, es necesario mencionar algunos razonamientos expresados en la resolución:

* El contenido del presente documento derivó del voto minoría que formularon los ministros José Ramón Cossío Díaz y José de Jesús Gudiño Pelayo, en relación con el amparo directo en revisión 23/2005, promovido por Roberto Julián O’Neill Level, Bortel Archibold Level, y otros.

[** Zuily Zárate Díaz.] 
A. El tema central consistió en determinar si la Zona Económica Exclusiva a la que alude el artículo 27 constitucional, es o puede ser considerada parte del territorio nacional, para efectos de sancionar la conducta delictiva cometida en dicha Zona y regulada en el artículo 194, fracción II del Código Penal Federal, pues se consideró que con base en la respuesta que se le dé al planteamiento anterior, se puede afirmar si se está ante un delito de introducción de narcóticos al país de manera consumada, o bien, no consumada.

Se puso de manifiesto que la Nación mexicana ejerce derechos de soberanía y jurisdicción sobre la denominada Zona Económica Exclusiva, en términos de la normatividad que rige a la materia, en donde los estados extranjeros gozan de derechos, libertades y obligaciones. Asimismo, se señaló que la Nación mexicana, como Estado parte de la Convención de las Naciones Unidas sobre el Derecho del Mar y como Estado ribereño de la Zona Económica Exclusiva, le corresponde legislar, por conducto del Congreso de la Unión, todo lo relacionado con dicha institución jurídica, en términos del párrafo octavo del artículo 27 de la Constitución, aspecto que se relaciona directamente con los derechos de soberanía y jurisdicción que tiene sobre esta Zona, la cual es considerada como patrimonio nacional, siendo un bien del dominio público.

Asimismo, se consideró que las normas de origen nacional y del orden internacional, permiten observar tres aspectos fundamentales, para establecer si dentro del concepto jurídico-político de territorio nacional, se comprende la Zona Económica Exclusiva, a saber: a) la facultad para crear las leyes en materia de derecho del mar; b) ejercicio de soberanía y c) ejercicio de jurisdicción.

Igualmente, en la resolución se sostuvo que ante este panorama normativo, el concepto jurídico-político de territorio nacional, circunscribe la aplicación de la ley penal del Estado — en este caso la Nación mexicana — de acuerdo al lugar donde se haya desplegado la conducta delictiva, por lo que dicha aplicación debe realizarse en aquellos lugares que estén sometidos a su soberanía, jurisdicción y en donde el Estado ejerza facultades legislativas. Por tanto, se señaló quese debía considerar a dicha Zona como territorio nacional, para efectos del artículo 194, fracción II del Código Penal Federal, en su modalidad de introducción de narcóticos a nuestro país, en virtud que la aplicación de la ley penal, teniendo en cuenta que el lugar de comisión del delito no se circunscribe únicamente a la extensión física o geográfica que conforma la materialidad del territorio, sino que partiendo de una concepción amplificadora de su concepto jurídico-político, también debe entenderse por el mismo todos aquellos lugares en donde la Nación mexicana ejerce los derechos y facultades de mérito. 
Lo anterior se fundó en el artículo 2 de la Ley Federal del Mar, en el sentido de que dicha ley es de jurisdicción federal, la cual rige en las zonas marinas que forman parte del territorio nacional y, en lo aplicable, más allá de éste, en las zonas marinas donde la Nación ejerce derechos de soberanía, jurisdicciones y otros derechos. Por su parte, el diverso artículo 2, fracción IX, de la Ley Orgánica de la Armada de México señala como una de las atribuciones de la armada de México, garantizar el cumplimiento del orden jurídico en las zonas marinas mexicanas, por sí o coadyuvando con las autoridades competentes, entre otros, en el combate al tráfico de estupefacientes y psicotrópicos.

Igualmente, se advirtió que el legislador, en el ámbito penal, contempló que en las zonas marinas mexicanas, dentro de las que se encuentra la Zona Económica Exclusiva, pueden desplegarse conductas delictivas, como podría ser la que se relaciona con el delito de narcotráfico, por lo que otorgó atribuciones a la Armada de México, para combatir dichas conductas, de acuerdo a la normatividad aplicable, atribuciones que sólo pueden ejercer considerando al territorio nacional, no sólo desde el punto de vista geográfico, sino también, como partes conformadoras de su concepto jurídico político, aquellos lugares en donde la Nación mexicana ejerce derechos de soberanía, jurisdicción y facultades legislativas; atribuciones que se complementan con las facultades conferidas a los tribunales de la federación en el sentido de ser competentes para conocer de los juicios penales que se relacionen con bienes nacionales, como lo es la Zona Económica Exclusiva, en términos del artículo 7 de la Ley de Bienes Nacionales trascrito en párrafos precedentes.

En consecuencia, se resolvió que se estaba en presencia del delito de introducción al país de narcóticos, consumado, contemplado en el artículo 194, fracción II, del Código Penal Federal.

No se comparten las consideraciones ni el sentido de la resolución, atento a los siguientes razonamientos:

B. Uno de los primeros acercamientos a la regulación de la jurisdicción exclusiva sobre los recursos marinos, situados más allá del mar territorial, fue la Proclamación del Presidente Truman el 28 de septiembre de 1945, en relación con la plataforma continental de los Estados Unidos. ${ }^{1}$ Esta última tuvo como principal finalidad la conservación y prudente utilización de los recursos naturales.

1 Nandan, S. N., "The Exclusive Economic Zone: A historical perspective”, Food and Agriculture Organization of the United Nations (FAO). Cfr. http://www.fao.org/docrep/s5280T/s5280t Op.htm. 
Sin embargo, el origen del concepto de la Zona Económica Exclusiva se encuentra en las diversas declaraciones unilaterales de soberanía de Chile y Perú en 1947, y de diversos países árabes en 1949. Dichas declaraciones tuvieron en común los siguientes aspectos: a) la jurisdicción sobre el lecho y el subsuelo marino; b) el mantenimiento del régimen sobre la libertad de navegación y de sobrevuelo, entre otras. ${ }^{2}$

En 1952, la Declaración de Santiago firmada por Chile, Ecuador y Perú, estableció el límite de 200 millas náuticas. Estos tres gobiernos reconocieron como uno de los principios más importantes de su política marítima internacional la posesión de soberanía y jurisdicción sobre dicha área adyacente. Desde ese momento, se pudo apreciar el surgimiento de dos tendencias paralelas en materia de reivindicaciones marítimas de este tipo: en primer lugar, aquellas que sólo buscaban el ejercicio de competencias del Estado para fines económicos específicos $\mathrm{y}$, en segundo lugar, aquellas que procuraban incrementar el ejercicio de competencias por el Estado ribereño con un sentido más territorialista, aun cuando no se reclamara formalmente un mar territorial de 200 millas. $^{3}$

Dichas tendencias habrían de encontrarse en las conferencias de la Naciones Unidas sobre el Derecho del Mar de 1958 y 1960 y, sobretodo, en el ámbito de las negociaciones de la Tercera Conferencia del Mar y sus trabajos preliminares. De ahí que la cuestión de la naturaleza jurídica de la Zona Económica Exclusiva no sólo quedara planteada desde un comienzo en las negaciones, sino que igualmente comenzara a resolverse paso a paso en cada una de las etapas por las que atravesó este proceso de formación de las nuevas normas del derecho internacional del mar.

Otra de las etapas de este proceso de formación, fue la Declaración de Santo Domingo de 1972, en la que participaron quince estados del Caribe, en ésta se utilizó por primera vez el término "mar patrimonial", poniendo énfasis en la jurisdicción patrimonial del Estado sobre los recursos y no sobre el mar patrimonial ${ }^{4}$. Los antecedentes de dicha Declaración son los acuerdos de Montevideo y Lima de 1970.

Por otro lado, los países de Asía y África definieron explícitamente el concepto en diversas sesiones del Comité Jurídico Consultivo Afro-Asiático: ${ }^{5}$ Co-

2 Idem.

3 Orrego Vicuña, Francisco, La Zona Económica Exclusiva: Régimen y Naturaleza Jurídica en el Derecho Internacional, Chile, Editorial Jurídica de Chile, 1991. pp. 11-13.

4 Cfr. Declaration of Santo Domingo of 9 June 1972.

5 Report of the Sub-Committee on the Law of the Sea by the Asian African Consultative Committee, Colombo, January 1971. 
lombo (1971), Yaoundé (1971), Lagos ${ }^{6}$ (1972) y en la Declaración de la Organización de la Unidad Africana (ADIS-ABEBA, 1973). ${ }^{7}$

Finalmente, como resultado de la Tercera Conferencia de las Naciones Unidas sobre el Derecho del Mar, celebrada de 1973 a 1982 con representantes de más de 150 países, fue abierta para su firma, en Montego Bay, Jamaica, la Convención de las Naciones sobre el Derecho del Mar de 1982. Dicha Convención entró en vigor el 16 de noviembre de 1994. La regulación de la Zona Económica Exclusiva, en la Convención, constituyó un equilibrio entre dos intereses contrapuestos: el de los países ribereños sobre los recursos de los espacios marítimos más allá de su mar territorial y, el de las potencias marítimas empeñadas en que se mantuvieran las libertades del mar de las que siempre habían disfrutado. ${ }^{8}$

Con base en los antecedentes anteriores, se puede afirmar que la Zona Económica Exclusiva se creó como respuesta a la necesidad de dotar al Estado costero de una serie de facultades específicas sobre la franja de mar adyacente a su mar territorial, relacionadas fundamentalmente con el aprovechamiento económico de esas aguas y, más concretamente, con la explotación de recursos vivos. ${ }^{9}$ Por ello, el régimen que se aplica a dicho espacio no es el de plena soberanía territorial ya que el resto de los estados de la comunidad internacional disfrutan también de algunos derechos en esta Zona, de entre los que destacan los vinculados con las comunicaciones y transporte internacionales.

C. Ahora bien, la Constitución Política de los Estados Unidos Mexicanos, en su artículo 42, determina que el territorio nacional comprende: "V. Las aguas de los mares territoriales en la extensión y términos que fija el Derecho Internacional y las marítimas interiores".

Igualmente, el párrafo octavo del artículo 27 constitucional, establece que:

La Nación ejerce en una zona económica exclusiva situada fuera del mar territorial y adyacente a éste, los derechos de soberanía y las jurisdicciones que determinen las leyes del Congreso. La zona económica exclusiva se extenderá a doscientas millas náuticas, medidas a partir de la línea de base desde la cual se mide el mar territorial. En aquellos casos en que esa extensión produzca superposición con las zonas económicas exclusivas de otros Estados, la delimitación de las respectivas

6 Report of the Thirteenth Session of the Asian African Consultative Committee, Lagos, January 1972 .

7 Sentencia No. T-141/96 de la Corte constitucional de Colombia.

8 Stevenson, Johon y Oxamn, Bernard H., "Third United Nations Conference on the Law of the sea: Geneva Session", AJIL, 1975, vol. 69, no. 1, pp. 1-30.

9 Carnerero Castilla, Rubén, El régimen jurídico de la navegación por la zona económica exclusiva, Madrid, Universidad Complutense de Madrid, 1999, p. 33. 
zonas se hará en la medida en que resulte necesario, mediante acuerdo con estos Estados.

De la lectura de los preceptos anteriores, se desprenden, en nuestra opinión, los siguientes problemas:

a) En primer lugar, la cuestión de la determinación de la anchura del Mar Patrimonial o Zona Económica Exclusiva, en virtud de la declaración unilateral del Estado Mexicano, sobre aquélla, es decir, de doscientas millas náuticas.

b) En segundo lugar, se debe de determinar qué tipo de atribuciones se ejercen sobre la Zona Económica Exclusiva.

Para dar respuesta al primer planteamiento, es decir, el relativo a la delimitación de los espacios marinos, los tribunales internacionales, específicamente, la Corte Internacional de Justicia se ha pronunciado sobre esta cuestión al resolver el problema de las pesquerías noruegas, entre el Reino Unido y Noruega, en donde señaló, de manera expresa, que la limitación de los espacios marítimos es una cuestión internacional, y que no puede depender de la sola voluntad del Estado ribereño, en los términos en que a él le parezca que debe expresarlo en su derecho nacional. ${ }^{10}$ Asimismo, este criterio se expresó en otro asunto de pesquerías entre Islandia contra el Reino Unido y la República Federal Alemana. ${ }^{11}$

En relación con el segundo problema, consideramos necesario acudir al Derecho Internacional, el que, a través de la Convención de la materia, establece claramente cuáles son las atribuciones que los estados ribereños tienen en la Zona Económica Exclusiva.

De este modo, el artículo 56 de la Convención de Naciones Unidas sobre el Derecho del Mar establece que en la Zona Económica Exclusiva, el Estado ribereño tiene:

a) Derechos de soberanía para los fines de exploración y explotación, conservación y administración de los recursos naturales, tanto vivos como no vivos de las aguas suprayacentes al lecho y del lecho y el subsuelo del mar, y con respecto a otras actividades con miras a la exploración y explotación económica de la zona, tal como la producción de energía derivada del agua de las corrientes y de los vientos;

b) Jurisdicción, con arreglo a las disposiciones pertinentes de esta Convención, con respecto a:

10 Cfr. Fisheries Case (United Kingdom v. Norway) International Court of Justice Reports, December 18th, 1951.

11 Cfr. North Sea Continental Shelf Cases, International Court of Justice Reports, February 20th 1969 
i) El establecimiento y la utilización de islas artificiales, instalaciones y estructuras:

ii) La investigación científica marina;

iii) La protección y preservación del medio marino;

c) Otros derechos y deberes previstos en esta Convención.

La disposición transcrita deja patente que el Estado ribereño no ejerce soberanía territorial sobre la Zona Económica Exclusiva como ocurre en el caso del mar territorial o las aguas interiores, sino sólo unos derechos para determinados fines y con relación a ciertas actividades. De este modo, los derechos que se reconocen sobre los recursos vivos constituyen la característica más relevante de este espacio. ${ }^{12}$

En cuanto al inciso a), referente a los "derechos de soberanía", éstos son concebidos no de una manera general, sino con un alcance funcional, pues se prevén con dos propósitos principales: a) el relativo a los fines de exploración y explotación, conservación de los recursos naturales, tanto vivos como no vivos, de las aguas suprayacentes, al lecho y del lecho y subsuelo del mar; y, b) se refiere a otras actividades con miras a la exploración y explotación económicas, como por ejemplo, la producción de energía derivada del agua, de las corrientes, y de los vientos. ${ }^{13}$

En cuanto al inciso b), referente a "la jurisdicción" del Estado ribereño se ejerce respecto de tres materias específicas: el establecimiento y utilización de islas artificiales, instalaciones y estructuras; la investigación científica marina; y, la protección y preservación del medio marino.

Del apartado anterior se infiere que la distinción entre "derechos de soberanía” y "jurisdicción” tiene evidentemente el propósito de indicar una graduación en la intensidad con que se manifiestan los derechos del Estado ribereño en este espacio, siendo menor en el segundo caso. ${ }^{14}$ De este modo, se considera que la utilización de términos diferentes pretende reflejar una graduación entre los derechos, pues la expresión "derechos de soberanía", referida al aprovechamiento de los recursos vivos y no vivos, destaca la exclusividad de su ejercicio, en la línea marcada por el denominado Nuevo Orden Económico Internacional, que fue establecido en la Resolución 3201 (S-VI) de la Asamblea General de las Naciones Unidas, el 1o. de mayo de 1974, uno de cuyos pilares fundamentales es, pre- 
cisamente, la plena soberanía permanente y el control de los estados sobre tales recursos y su explotación. ${ }^{15}$

En cuanto al inciso c), se trata de derechos y deberes, diferentes a los señalados en los dos incisos anteriores, que pueden emanar de otras disposiciones de la Convención. Por ejemplo, la jurisdicción exclusiva sobre islas artificiales, instalaciones y estructuras (art. 60.2); el derecho a tomar las medidas necesarias para garantizar el cumplimiento de sus leyes relativas a la exploración, explotación, conservación y administración de los recursos vivos (art. 73), entre otras.

Ahora bien, consideramos que esta forma del Derecho Internacional, es la que se reflejó en la Ley Federal del Mar ${ }^{16}$ en el artículo 2 que establece lo siguiente: "La presente Ley es de jurisdicción federal, rige en las zonas marinas que forman parte del territorio nacional y, en lo aplicable, más allá de éste en las zonas marinas donde la Nación ejerce derechos de soberanía, jurisdicciones y otros derechos. Sus disposiciones son de orden público, en el marco del sistema nacional de planeación democrática".

Por lo anterior, para efectos del análisis del caso que nos ocupa, es necesario señalar que la Ley Federal del Mar, con base en lo dispuesto en la Convención del Mar, distingue entre mar territorial, zona contigua, zona económica exclusiva, plataforma continental y alta mar. En este sentido, en el mar territorial la Nación ejerce soberanía plena; en la zona contigua, el Estado está facultado únicamente para tomar las medidas de fiscalización necesarias para prevenir y sancionar las infracciones de sus leyes y reglamentos aduaneros, fiscales, de inmigración o sanitarios que se cometan en su territorio o en su mar territorial ${ }^{17} \mathrm{y}$, en la Zona Económica Exclusiva se poseen derechos de soberanía restringidos, es decir, sobre las materias específicamente señaladas en la Convención y/o Ley.

De lo anterior se desprende que en cada una de estas zonas se ejercen diferentes grados de soberanía, es decir, en el mar territorial, se ejerce soberanía plena; en la zona contigua, se encuentra limitada a la prevención y sanción de posibles infracciones que pudieran cometerse en el territorio, en las aguas mari-

15 Díez de Velasco, M., Instituciones de derecho internacional público, 11a. ed., Madrid, Tecnos, 1997, t. I, pp. 421-422.

16 Publicada en el Diario Oficial de la Federación el 8 de enero de 1986. De acuerdo con la exposición de motivos de dicha Ley, México participó muy activamente en la Convención y fue el segundo país en firmar la Convención del Mar en 1982, sin embargo, se esperaba un largo periodo para que esta entrara en vigor, lo cual no era conveniente para la protección de los intereses mexicanos; por lo tanto, se decidió que el único medio para dotar al país de la autoridad jurídica esencial para ejercer sus derechos en el ámbito marino era la adopción de legislación interna que incorporase, al ordenamiento nacional, las normas del nuevo orden jurídico internacional en la materia.

17 Véase artículo 33 de la Convención de las Naciones Unidas sobre el Derecho del Mar. 
nas interiores o en el mar territorial mexicanos; en la Zona Económica Exclusiva, se encuentra limitada únicamente a lo establecido en el artículo 56 de la Convención del Mar (y el artículo 46 de la Ley Federal del Mar).

Del análisis de la Convención se infiere que la finalidad de la existencia de una Zona Económica Exclusiva es permitir la protección, exploración, explotación y conservación de los recursos marinos a los países contiguos, respetando los derechos de los que usualmente habían gozado los demás estados. Por lo tanto, los derechos y jurisdicción que los estados ribereños pueden ejercer en dicha Zona quedan restringidos al fin mencionado, es decir, las facultades del estado ribereño, enumeradas principalmente en el artículo 56 de la Convención, no pueden ser discordantes con el fin para el cual fue creado la propia Zona, al cual, definitivamente, no corresponde la aplicación de toda la normatividad penal de un Estado, mediante una decisión unilateral.

Esto es así, toda vez que la limitación de los espacios marítimos es una cuestión internacional, y que no puede depender de la sola voluntad del Estado mexicano arrogarse derechos de soberanía en la Zona Económica Exclusiva, en los términos en que a él le parezca que debe expresarlo en el derecho nacional, pues una declaración unilateral de esta naturaleza, conllevaría al sometimiento al Estado mexicano a las determinaciones de la Corte Internacional de Justicia, por violaciones al Derecho Internacional.

Ahora bien, en la resolución, emitida por los Ministros de la mayoría, se afirma que la Zona Económica Exclusiva debe considerarse como parte perteneciente al territorio nacional, en virtud de que en dicha Zona pueden desplegarse conductas delictivas que sólo pueden sancionarse si se le da este carácter. Se aduce que dicho carácter deriva no solamente de los atributos físicos o geográficos, sino también por el sólo hecho de ejercer derechos de soberanía y jurisdicción por parte del Estado mexicano.

No estamos de acuerdo con la afirmación anterior, toda vez que la Ley Federal del Mar es clara al señalar:

1) En su artículo 2 que dicho ordenamiento rige en las zonas marítimas que forman parte del territorio nacional y, en lo aplicable, más allá de éste, en las zonas marinas donde la Nación ejerce derechos de soberanía, jurisdicciones y otros derechos. Es decir, existen zonas marinas, que no son territorio nacional, en las que la Nación ejerce derechos de soberanía, jurisdicción y otros derechos. Por lo tanto, este artículo no puede referirse sino, precisamente, a las zonas marinas tales como la Zona Económica Exclusiva, que se encuentra más allá del mar territorial y en la que se ejercen los derechos de soberanía, jurisdicciones y otros derechos enunciados en su artículo 46. 
2) En su artículo 46 que el Estado ejerce sobre la Zona Económica Exclusiva: uno, derechos de soberanía restringida a diversos fines; dos, jurisdicción, con relación con a la Ley, su Reglamento y el derecho internacional y, tres, otros derechos y deberes fijados por la Ley, su Reglamento y el derecho internacional. ${ }^{18}$

También se sustenta, en la mencionada determinación, que la Zona Económica Exclusiva forma parte del patrimonio nacional, constituyendo un bien de dominio público, en donde sólo los Tribunales de la Federación son competentes para conocer de los juicios penales que se relacionen con la misma; lo anterior de conformidad con los artículos 1, fracción I, 2, fracción II y 7 de la de la Ley General de Bienes Nacionales. ${ }^{19}$

Contrariamente a esta posición, se considera que forman parte del patrimonio nacional los recursos de la Zona Económica Exclusiva y los derechos limitados que se ejercen sobre dicha zona, no la zona misma, y que el concepto de territorio nacional es distinto del concepto de patrimonio nacional.

La afirmación anterior, encuentra apoyo en una de las resoluciones emitidas por el Tribunal Internacional del Derecho del Mar, en la que se señaló lo siguiente: ${ }^{20}$

En relación con la Zona Económica Exclusiva, el artículo 56 establece determinados derechos de soberanía, pero solamente respecto a propósitos especificos, ninguno de los cuales es materia de este asunto. La distinción entre la 'soberanía' y los 'derechos de la soberanía' que se ejercen en la zona económica exclusiva es demasiado elemental para efectos de requerir la autoridad, especialmente, de este tribunal para pronunciarse al respecto.

Por ejemplo, en palabras de Orrego Vicuña en la página 47, señala:...

El Estado ribereño sólo puede ejercer derechos de soberanía y jurisdicción en aquellas materias que funcionalmente le son conferidas...

Para citar al Embajador Jorge Castañeda, que estuvo presente en la Conferencia del Derecho del Mar:...

En esta Zona, los estados ribereños ejercen derechos de soberanía sobre los recursos, para los propósitos de exploración y explotación, pero no ejercen derechos de soberanía sobre ella, contrario a lo que sucede en el caso del mar territorial. Esta es su principal característica.

18 Este artículo señala los mismos derechos y jurisdicción que el artículo 56 de la Convención del Mar mencionada.

19 Publicada en el Diario Oficial de la Federación el 8 de enero de 1982, vigente hasta el 21 de mayo de 2004.

20 The M-V "Saigar" (No. 2). Case (Saint Vincent and the Grenadines v. Guinea) July 1st 1999. 
Es decir, en esta decisión del Tribunal del Mar se reconoció que los derechos de soberanía que ejercen los estados ribereños están restringidos a los propósitos señalados en el artículo 56 de la Convención sobre el Derecho del Mar. Asimismo, se advierte de la trascripción anterior, que dicha postura también fue sostenida por doctrinarios, así como por el embajador mexicano Jorge Castañeda en la Conferencia del Derecho del Mar, en el sentido de considerar de manera restringida los derechos de soberanía que ejercen los estados ribereños en la Zona Económica Exclusiva.

Con la finalidad de fortalecer los anteriores razonamientos, revisamos sentencias de cortes supremas de algunos países, así como una resolución emitida por el Tribunal del Mar, de ello pudimos inferir que este planteamiento no ha representado mayor problema para dichos órganos, toda vez que las resoluciones que se refieren a esta materia tratan solamente cuestiones relativas a los derechos que la Convención del Mar les otorga, entre otros, pesca, explotación y conservación de recursos:

El Tribunal del Mar señaló que:

57. Es posible adelantar argumentos en apoyo a la caracterización del 'aprovisionamiento y recarga de combustible de buques pesqueros' como una actividad cuya regulación puede ser asimilada a la regulación, en ejercicio, por parte del Estado ribereño, de sus derechos soberanos para explorar, explotar, conservar y administrar los recursos vivos en la zona económica exclusiva. Puede argumentarse que el recargar combustible es, por naturaleza, una actividad accesoria a las actividades propias de la nave que es recargada. $\mathrm{Al}$ respecto, pueden señalarse algunos ejemplos de prácticas de los Estados. El artículo 1 de la Convención para la Prohibición de la Pesca con Redes de Deriva y de Gran Escala en el Pacífico Sur del 23 de noviembre de 1989 define 'actividades de pesca con redes de deriva' entre las partes como cualquier 'transporte, transferencia entre naves y procesamiento de la pesca obtenida con redes de deriva, y la cooperación en el aprovisionamiento de comida, combustible $\mathrm{u}$ otras reservas para buques equipados para o involucrados en la pesca con redes de deriva. Como se establece en el caso 'Saint Vincent and the Grenadines', Guinea, en su decreto-ley no. 4/94 del 2 de agosto de 1994, requiere autorización por parte del Ministerio de Pesca para operaciones 'relacionadas' con la pesca, y Sierra Leona y Marruecos rutinariamente autorizan el recargo de combustible de buques pesqueros fuera de puerto.

58. También es posible adelantar argumentos, aun cuado Guinea no se refirió a esta cuestión, en apoyo a la visión opuesta, consistente en que el cargar combustible en el mar debe ser clasificado como una actividad independiente, cuyo régimen legal debe ser el de la libertad de navegación (o tal vez — cuando es 
llevada a cabo en la zona económica exclusiva- el previsto en el mencionado artículo 59 de la Convención). La posición de los Estados, con zonas económicas exclusivas, que no han adoptado reglas respecto al aprovisionamiento y recarga de combustible de buques pesqueros puede interpretarse como indicando que dichos Estados no consideran que esta actividad se encuentre en conexión con las actividades de pesca. En apoyo de esta visión puede argumentarse, asimismo, que el aprovisionamiento y recarga de combustible de buques pesqueros no se encuentra incluido en la lista de materias a las que las leyes y regulaciones del Estado ribereño pueden referirse de acuerdo con el artículo 62, párrafo 4 de la Convención.

\section{La Corte Constitucional de Colombia señaló que:}

\section{La soberanía económica}

El artículo 73 de la Convención sobre el derecho del mar habla de derecho de soberanía. Es obvio que no se trata de una soberanía plena la que el Estado ribereño puede ejercer sobre la zona económica exclusiva...

Esta zona de soberanía económica se refiere a la explotación de los recursos naturales, tanto vivos como no vivos, asi como a la producción de la energía derivada del agua, de las corrientes y de los vientos; pero no se aplica al espacio marítimo, en sí mismo, ya que éste permanece abierto a las libertades tradicionales de navegación y de comunicación. ${ }^{21}$

\section{Por su parte, el Tribunal Constitucional español señaló que:}

Pues bien, el art. 132.2 CE deja bien claro que integran el dominio público del Estado aquellos bienes que una Ley determine, y en cualquier caso: «la zona marítimo-terrestre, las playas, el mar territorial, y los recursos naturales de la zona económica y la plataforma continental». Nadie pone en cuestión, pues, que el mar territorial pertenece al Estado en cuanto bien demanial, pero ello no significa que en dicho espacio marítimo no puedan ejercerse competencias como la actuada por la Junta de Andalucía (protección de espacios naturales mediante la declaración y gestión de Parque Natural), siempre que el espacio a proteger constituya una unidad, un ecosistema, y justifique un tratamiento conjunto de sus zonas terrestre y marítima para que tal protección sea coherente y efectiva...

No es ésta una conclusión que se obtenga por inferencias, mas o menos razonables, sino que viene avalada por las Cortes Generales que, al promulgar la Ley 4/1989, de 27 de marzo, de conservación de los espacios naturales y de la flora y fauna silvestres, incluyó en ella el art. 10.1, calificado de norma básica 
(Disposición adicional quinta), a cuyo tenor: "Aquellos espacios del territorio nacional, incluidas las aguas continentales, y los espacios marítimos sujetos a la jurisdicción nacional, incluidas la zona económica exclusiva y la plataforma continental, que contengan elementos y sistemas naturales de especial interés o valores naturales sobresalientes, podrán ser declarados protegidos de acuerdo con lo regulado en esta Ley”. En consecuencia, la declaración de un espacio natural protegido, en este caso de un Parque Natural, por quien ostenta exclusiva competencia para ello (en este caso, la Comunidad Autónoma de Andalucía, ex art. 13.7 de su Estatuto de Autonomía) puede comprender, sin constituir extralimitación territorial reprochable, ni excepcionalidad alguna, espacios de mar territorial en tanto en cuanto los mismos se integren en la unidad biológica o ecosistema objeto de preservación y tutela. Y es que territorio no se identifica aquí ni es coextenso con «espacio natural», pues no es tanto límite físico del ejercicio de competencias (más bien, delimitación) cuanto objeto de sus potestades o ámbito de ejercicio de sus funciones..." 22

También debe tenerse en cuenta que la Ley 15/1978, de 20 de febrero, cuyo art. 1 se refiere a la denominada zona económica exclusiva, extiende ésta hasta doscientas millas a partir del límite exterior del mar territorial español. De lo expuesto se deriva que, en principio, la competencia autonómica sobre el «marisqueo» puede ejercerse en el ámbito de las aguas llamadas exteriores, es decir, en el mar territorial y en la zona económica exclusiva, puesto que ni el art. 148.1.11 CE ni el art. 27.15 EAG limitan esta competencia a las llamadas «aguas interiores». Así lo confirma la STC 103/1989, que declaró que las competencias de la Comunidad Autónoma de Galicia en materia de «marisqueo» y «acuicultura» no están circunscritas estatutariamente a los límites de las aguas interiores. ${ }^{23}$

Ahora bien, siguiendo los razonamientos del embajador Castañeda, la Zona Económica Exclusiva tiene una naturaleza jurídica sui generis, en virtud de que no forma parte del mar territorial ni de la alta mar, ni puede ser asimilada a ninguno de estos espacios. De la misma manera, Churchill y Lowe sostienen que:24

Los artículos 55 y 86 de la Convención sobre el Derecho del Mar son claros en señalar que la Zona Económica Exclusiva no tiene un carácter residual perteneciente a la alta mar. Igualmente son claros en que la Zona Económica Exclusiva no tiene un carácter residual perteneciente al mar territorial... en cambio la Zona Económica Exclusiva debe considerarse como una zona funcional separada , de un carácter sui generis, situada entre el mar territorial y la alta mar.

22 Conflictos positivos de competencia acumulados 38/2002, 14/2/2002.

23 Recurso de inconstitucionalidad 9/2001.

24 Churchill R.R and Lowe, A.V, The Law of the Sea, 1983, Manchester University Press, pp. 129 y 130. Cfr. Orrego Vicuña, op., cit., p. 28. 
En este mismo sentido, en un Informe del Comité Internacional sobre la Zona Económica Exclusiva de la Internacional Law Association ${ }^{25}$ en relación con el artículo 55 de la Convención se estableció que:

A la luz de esta disposición es extremadamente difícil sostener la tesis de que la Zona Económica Exclusiva es parte de la alta mar. Las palabras "régimen jurídico específico" sólo pueden significar que cualquiera que sea el régimen jurídico de la Zona Económica Exclusiva es diferente tanto del mar territorial como de la alta mar. Es una Zona que comparte las características de ambos regímenes, pero que no pertenece a ninguno.

Sin embargo, siendo el régimen de la Zona Económica Exclusiva una unidad, integrada en lo fundamental por los artículos 55 a 75 de la Convención, le son aplicables al régimen de la Zona Económica Exclusiva algunas de las disposiciones relativas a la alta mar siempre y cuando no se contrapongan a su régimen. En este sentido, el artículo 58 de la Convención establece lo siguiente:

1. En la zona económica exclusiva, todos los Estados, sean ribereños o sin litoral, gozan, con sujeción a las disposiciones pertinentes de esta Convención, de las libertades de navegación y sobrevuelo y de tendido de cables y tuberías submarinos a que se refiere el artículo 87, y de otros usos del mar internacionalmente legítimos relacionados con dichas libertades, tales como los vinculados a la operación de buques, aeronaves y cables y tuberías submarinos, y que sean compatibles con las demás disposiciones de esta Convención.

2. Los artículos 88 a 115 y otras normas pertinentes de derecho internacional se aplicarán a la zona económica exclusiva en la medida en que no sean incompatibles con esta Parte.

3. En el ejercicio de sus derechos y en el cumplimiento de sus deberes en la zona económica exclusiva en virtud de esta Convención, los Estados tendrán debidamente en cuenta los derechos y deberes del Estado ribereño y cumplirán las leyes y reglamentos dictados por el Estado ribereño de conformidad con las disposiciones de esta Convención y otras normas de derecho internacional en la medida en que no sean incompatibles con esta Parte.

En relación con el primer párrafo de este artículo, al contrario de lo que ocurre con los derechos del Estado ribereño, la Convención no describe con suficiente detalle, la naturaleza y alcances de las competencias que los terceros es-

25 "Report of the International Committee on the Exclusive Economic Zone", Report of the Sixty-First Conference, Paris, 1984, pp. 183-207. 
tados disfrutan en la Zona Económica Exclusiva y, como consecuencia de ello, se han suscitado discusiones acerca de si cualitativamente se trata de las mismas libertades que disfrutan en el alta mar. ${ }^{26} \mathrm{Sin}$ embargo, dado que cada régimen mantiene su propia esfera de aplicación, cuando estas libertades se aplican a la Zona Económica Exclusiva, están sujetas a mayores condiciones y restricciones que cuando se aplican en la alta mar. Por tanto, se considera que, contrario a lo argumentado en la discusión de la presente resolución, el hecho de que algunos aspectos del régimen de la Zona Económica Exclusiva se relacionen con las libertades del alta mar, no significa que el régimen de este último se compenetre con el de aquélla. Al respecto, el Embajador venezolano, Andrés Aguilar explicó acerca de las negociaciones que condujeron a un acuerdo sobre la Zona que:27 "Tampoco cabe dudar de que la zona económica exclusiva no es ni la alta mar ni el mar territorial. Es una zona sui generis... los derechos a los recursos corresponden a los estados ribereños y, en al medida en que no se infrinjan esos derechos, todos los demás estados disfrutarán de las libertades de navegación y comunicación."

Ahora bien, respecto al segundo párrafo del artículo 58 de la Convención, la aplicación de los preceptos 88 a 115 (parte del régimen del alta mar), está sujeta también a la compatibilidad con los artículos 55 a 75 (régimen de la Zona Económica Exclusiva).

De este modo, algunas de las disposiciones relativas a la alta mar son de aplicación general a todo el ámbito marítimo, incluso al mar territorial, tales como el derecho de persecución regulado en el artículo 111.1 de la Convención que establece que se podrá emprender al persecución de un buque extranjero cuando las autoridades competentes del Estado ribereño tengan motivos fundados para creer que el buque ha cometido una infracción de las leyes o reglamentos de ese Estado. La persecución habrá de empezar mientras el buque extranjero o una de sus lanchas se encuentre en la aguas interiores, las aguas archipelágicas, en el mar territorial o en la zona contigua del estado perseguidor y sólo podrá continuar fuera del mar territorial o de la zona contigua a condición de no haberse interrumpido. ${ }^{28}$

26 Carnerero Castilla Rubén, op. cit. p. 37.

27 Aguilar, Andrés, Texto presentado por el Presidente de la Segunda Comisión. Doc/CONF.62/WP.8/Rev.1/Parte II, párrs. 17-18, 6 de mayo 1976, Documentos Oficiales, Vol. V, 1976. Cfr. Gómez-Robledo Verduzco, Alonso, El nuevo derecho del mar: Guía introductiva a la Convención de Montego Bay, México, UNAM, Instituto de Investigaciones Jurídicas-Miguel Ángel Porrúa, 1986, p. 429.

28 Al respecto, Brownlie, Ian, Principles of International Law, 5a. ed., United Kingdom, Oxford University Press, 1966, pp. $242-245$. 
Cabe señalar que si el buque extranjero se encuentra en la zona contigua definida en el artículo 33, la persecución no podrá emprenderse más que por violación de los derechos para cuya protección fue creada dicha zona. ${ }^{29}$

De esta forma, consideramos que, en el caso, esta posibilidad sólo podría presentarse si los colombianos hubieren navegado en el mar territorial, y se hubiere comenzado, a partir de esta zona, la persecución, de manera no interrumpida, por presuntas violaciones al orden jurídico mexicano; o partir de la Zona Contigua, por violación a los derechos para cuya protección fue creada dicha zona, de acuerdo con el artículo 33 de la Convención, es decir, la aplicación de las medias de fiscalización necesarias para prevenir y sancionar las infracciones a la leyes y reglamentos aduaneros, fiscales, de inmigración o sanitarios cometidos en su territorio o en su mar territorial.

En este orden de ideas, en la Zona Económica Exclusiva son aplicables algunos principios y reglas propios de alta mar como por ejemplo la utilización de este espacio excluidamente con fines pacíficos (art. 88); ningún Estado podrá someterlo a su soberanía (art. 89); todos los estados tienen derecho a que los buques de su nacionalidad naveguen por sus aguas aplicándoseles los principios establecidos para el alta mar, y en concreto, los que se refieren al pabellón (arts. 91 a 94); o a la inmunidad de algunos de ellos, de su capitán y de su tripulación (arts. 95 a 97); los capitanes deberán prestar auxilio a las personas que se encuentren en el mar (art. 98); quedando prohibido el transporte de esclavos, que será debidamente castigado (art. 99). Además, todos los estados tienen el deber de cooperar en la represión de la piratería y la facultad expresa de apresar un buque o aeronave pirata y decidir las penas que deban de imponerse por piratería (arts. 100 a 107); cooperar para reprimir el tráfico ilícito de estupefacientes y sustancias psicotrópicas (art. 108), entre otras. ${ }^{30}$

En relación con este último punto, se adujo que la Convención de las Naciones Unidas contra el Tráfico de Estupefacientes y Sustancias Psicotrópicas ${ }^{31}$ es aplicable al caso que nos ocupa. En efecto, dicha Convención se refiere a la materia que regula el artículo 194 del Código Penal Federal y es aplicable en nuestro país.

Sin embargo, dicha Convención se refiere a la cooperación y ayuda mutua que deben prestarse los países signantes para impedir el tráfico de drogas. En

29 Artículo 111.1 de la Convención del Mar.

30 Nótese que en el caso de piratería existe una facultad expresa para apresar y sancionar lo que no sucede en el caso de tráfico ilícito de estupefacientes y sustancias psicotrópicas.

31 Aprobada el 19 de diciembre de 1988 por la Conferencia en su sexta sesión plenaria celebrada en Austria. México, entró en vigor en el 11 de abril de 1990. 
este sentido, el artículo 17.9 de dicha Convención, ubicada en el rubro denominado "Tráfico Ilícito por Mar" señala que las partes cooperarán en todo lo posible para eliminar el tráfico ilícito por mar, de conformidad con el derecho marítimo internacional, por lo que considerarán la posibilidad de concertar acuerdos o arreglos bilaterales y regionales para llevar a la práctica las disposiciones establecidas en este artículo o hacerlas más eficaces.

De la disposición mencionada, se infiere que el combate al narcotráfico, fuera del territorio nacional, y precisamente por no ser estado alguno soberano en dicho espacio, requiere de la cooperación, vía acuerdos o arreglos bilaterales, entre los estados. Al respecto, la Comisión de Estupefacientes del Consejo Económico y Social de la Organización de las Naciones Unidas. ${ }^{32}$ en el Tercer Informe bienal sobre las Medidas para fomentar la cooperación judicial, señaló que de las respuestas recibidas al cuestionario para los informes bienales, ${ }^{33}$ aproximadamente un tercio (31\%) de los estados que contestaron había celebrado acuerdos bilaterales o multilaterales sobre el tráfico ilícito por mar. ${ }^{34}$

Cabe mencionar, que México ha celebrado únicamente dos acuerdos en materia de Zona Económica Exclusiva, uno, con el gobierno de Guatemala ${ }^{35}$ denominado Acuerdo para la Vigilancia de las Zonas marítimas Fronterizas en el Océano Pacífico, tanto en el Mar territorial, como en la Zona Económica Exclusiva y, otro, con el Gobierno de Cuba denominado, Acuerdo sobre la Delimitación de los Espacios Marítimos de ambos países en las áreas en que dichos espacios serán colindantes en virtud del establecimiento de la Zona Económica Exclusiva de México y la eventual creación de una Zona Económica de Cuba (o

32 E/ CN.7/2005/2/Add.3 de enero de dos mil cinco.

33 Dicho cuestionario se lleva a cabo, de acuerdo con la Declaración Política aprobada por la Asamblea General en su Vigésimo periodo Extraordinario de sesiones (Resolución S- 20/2 de la Asamblea en que se exhorta a todos lo estados a informar, cada dos años, a la Comisión de Estupefacientes sobre sus esfuerzos por cumplir las metas y objetivos para 2003 y 2008.

34 Uno de los principales acuerdos multilaterales citados fue el Acuerdo Contra el Tráfico Ilícito por Mar del Consejo de Europa, por el que se pone en práctica el artículo 17 de la Convención de 1988 y una serie de tratados de cooperación en materia aduanera. Cabe mencionar que en sus artículos 6 a 10, señala que el Estado Ribereño que sospeche que una embarcación de otro Estado está realizando tráfico de drogas en la Zona Económica Exclusiva del Estado ribereño, puede solicitar al Estado, cuya bandera enarbola dicha embarcación, lo autorice para detener, abordar o aplicar las sanciones adecuadas. Cfr. Churchill R. R and Lowe A.V, The Law the Sea, 3a. ed., Melland Schill Studies in International Law, 1999, pp. 170 y 171.

35 Entró en vigor el 17 de agosto de 1989. Véase, http://tratados.sre.gob.mx/BusquedaGlobal. htm. 
su equivalente). ${ }^{36}$ Sin embargo, en ninguno de ellos, se regula la materia de tráfico ilícito de estupefacientes y sustancias psicotrópicas.

Por esta razón, se considera que el supuesto establecido en el artículo 2 de la Ley Orgánica de la Armada de México, únicamente tendría aplicación, en caso de celebrarse los acuerdos a que hace referencia el artículo 17.9 de la Convención de las Naciones Unidas contra el Tráfico de Estupefacientes y Sustancias Psicotrópicas.

En este sentido, se tiene conocimiento de que existen diversos acuerdos de cooperación celebrados por México con otros estados - Israel, Brasil, Rusia, Uruguay, Panamá y Colombia - en materia de lucha contra el narcotráfico. Sin embargo, en ninguno de ellos, específicamente en el caso colombiano, se regula su competencia para el caso de que dichas conductas sean cometidas en el mar.

Finalmente, México ha celebrado con los Estados Unidos un Tratado sobre Límites Marítimos; sin embargo, éste se refiere a establecer la demarcación de los límites marítimos entre ellos y no afecta, de manera alguna, las posiciones de cualquiera de las dos partes respecto a la extensión de las aguas interiores, del mar territorial, o de los derechos de soberanía o de la jurisdicción que les corresponden de conformidad con el Derecho internacional. ${ }^{37}$

Con la finalidad de fortalecer nuestra posición, queremos hacer hincapié en la participación del Embajador Jorge Castañeda, durante las negociaciones de la Conferencia respecto de la Zona Económica Exclusiva en la que manifestó lo siguiente: ${ }^{38}$

El principio básico...era la naturaleza jurídica sui generis de la zona entre 12 y 200 millas, esto es, la zona no era un mar territorial con excepciones a favor de terceros estados, ni tampoco alta mar con excepciones a favor del Estado ribereño, sino una zona sujeta a un nuevo régimen en el derecho del mar. En esa zona, el Estado ribereño ejercía derechos de soberanía sobre los recursos, para los propósitos de exploración y explotación, pero no ejercía sobre la zona misma, como en el caso del mar territorial. Esta era su principal característica. Esta fue la tesis que finalmente prosperó y se incorporó en la Convención.

\section{htm.}

36 Entró en vigor el 26 de julio de 1976. Véase, http://tratados.sre.gob.mx/BusquedaGlobal.

37 Véase el artículo 3o del Tratado sobre Límites Marítimos entre los Estados Unidos Mexicanos y los Estados Unidos de América, publicado en el Diario Oficial de la Federación el 22 de enero de 1979.

38 Aguilar, Andrés, Texto presentado por el Presidente de la Segunda Comisión. Doc/CONF.62/WP.8/Rev.1/Parte II, párrs. 17-18, 6 de mayo 1976. 
Por todo lo anterior, nos manifestamos en contra de las consideraciones y del sentido de la resolución aprobada por la mayoría, toda vez que, en primer lugar, desde nuestro punto de vista, la Zona Económica Exclusiva no forma parte del territorio nacional y, en segundo lugar, el Estado mexicano no puede aplicar su normatividad penal de forma unilateral, ya que sólo ejerce derechos de soberanía, tiene jurisdicción y facultades para crear leyes de acuerdo con los supuestos establecidos "expresamente" en el artículo 56 de la Convención sobre el Derecho del Mar y en el 46 de la Ley Federal del Mar.

José Ramón COSSÍO DÍAZ*

* Se agradece el apoyo de la licenciada Mónica Castillejos y de Pilar Diez para la elaboración de este documento. 